\title{
Swimming as an accretive practice in healthy blue space
}

\author{
Ronan Foley* \\ Department of Geography, Rhetoric House, Maynooth University, Maynooth, Co. Kildare, Ireland
}

\section{A R T I C L E I N F O}

\section{Article history:}

Received 21 October 2015

Received in revised form

2 December 2016

Accepted 6 December 2016

\section{Keywords:}

Swimming

Blue-space

Therapeutic accretion

Affect

Ireland

\begin{abstract}
A B S T R A C T
Cultural geographers are increasingly interested in research on water and water-based practices as sites of study. Parallel literatures on therapeutic landscapes, especially emergent work on healthy blue space, have also begun to explore emotional geographies. This paper is an empirical study of outdoor swimming in Ireland with a specific focus on health and wellbeing. A key aim is to uncover evidence on how specific blue places and practices enable health. The idea of a continuum is utilised to link theory and practice and connect rather than divide affect, feeling and emotion. This is articulated through a set of embodied experiential practices that proposed swimming as a process of therapeutic accretion. Both personal and shared histories are used to identify the importance of both swimming practices and places to show how therapeutic accretions emerge to build healthy resilience. Additional insights suggest aspects of embodied health that are enhanced by outdoor swimming, especially in relation to bodies perceived to be inactive due to age, illness or disability. While the risks are not ignored, the need to better value outdoor swimming in cooler climates for public health is proposed, suggesting new directions for research on outdoor swimming to simultaneously capture active and passive embodied and emotional experiences within blue space.
\end{abstract}

() 2016 Elsevier Ltd. All rights reserved.

\section{Introducing outdoor swimming: water, health and place}

"Swimming stretches my body beyond its earthly limits, helping to soothe every ache and caress every muscle. But it's also an inward journey, a time of quiet contemplation, when, encased in an element at once hostile and familiar, I find myself at peace" (Sherr, 2012: 5).

In recent cultural geographical writing, oceans, seas and other bodies of water have been re-discovered as sites and subjects of interest (Ryan, 2012; Anderson and Peters, 2014; Brown and Humberstone, 2015). Earlier writing on coastal and inland settings focused on how water and swimming historically improved and sustained human health and wellbeing (Deakin, 1999; Parr, 2011; Sherr, 2012). More recent texts document experiential human responses to the sea and its non-human subjects and to a range of practices within and around it (Hoare, 2013). In all cases, those experiences and practices are shaped by explicit references to emotions and feelings that emerge in place (Edensor, 2010). In the ever-widening range of writing on emotional geographies, health

\footnotetext{
* Corresponding author.

E-mail address: ronan.foley@nuim.ie.
}

and wellbeing have also become increasingly explicit dimensions (Davidson et al., 2005; Parr and Davidson, 2010), while psychologists have also explored nature-based health (Hartig et al., 2015) How those emotional and healing strands build and come together as a therapeutic accretion through the practice of swimming within 'healthy blue space' is at the heart of this paper (Foley and Kistemann, 2015).

Such research in health geography has traditionally been associated with two separate but closely related strands of literature; therapeutic landscapes and healthy spaces Therapeutic landscapes have been defined as, "a geographic metaphor for aiding in the understanding of how the healing process works itself out in places (or in situations, locales, settings, milieus)" (Gesler, 1992: 743). This is the starting point in thinking about blue space, defined by Foley and Kistemann (2015: 158) as; "health-enabling places and spaces, where water is at the centre of a range of environments with identifiable potential for the promotion of human wellbeing". Such spaces have become fertile settings for health geographers working on well-being and place, with a focus on more qualitative approaches that reflect therapeutic landscapes perspectives (Coleman and Kearns, 2015; Foley, 2015).

A second and closely linked strand of literature on healthy spaces, has antecedents in environmental psychology and environmental health (Kaplan, 1995; Hartig et al., 2015), More typically 
experimental and quantitative in focus, such research traces active and passive associations between place and wellbeing (Mitchell, 2013; Pitt, 2014). Specific blue space studies, incorporating both water and skies, explore how health is enabled in a range of global settings (Völker and Kistemann, 2011, 2015; Wheeler et al., 2012; White et al., 2013)). More recently, Duff (2011) has called for better understandings of what he terms ' (health-) enabling places' and how they work. Emerging literatures on diving, surfing and swimming highlight how particular emotional encounters - on, in and under water - shape health in both physical and imaginative forms within blue space (Evers, 2009; Merchant, 2011; Foley, 2015). Such experiential and affective perspectives remain central in this work.

This study of outdoor swimming focuses on how blue space enables (and occasionally impairs) health. Swimmers' accounts of the physical act of swimming and more emotional dimensions of the experience uncover how place has an additionally significant role (Edensor, 2010). The empirical material draws from a qualitative study at outdoor coastal swimming locations in Ireland that combines (auto)ethnography, oral history and visual research with swimmers. The findings indicate how health and wellbeing emerge from an accretive practice within blue space, through repeated affective and emotional encounters (Edensor, 2010; Duff, 2012).

\section{Emotional geographies within therapeutic landscapes}

\subsection{Affective and emotional geographies}

In discussing emotion and place, debates on key theoretical terms such as feeling and especially affect, feature prominently, with complex associated definitions (Duff, 2010; Pile, 2010). Spinney (2015: 235) suggests that, "the study of affect is concerned with how emotions, sensations, atmospheres and feelings arise out of relational encounters between objects, spaces and people". Affect is also a central theme in writing on non-representational theories (Thrift, 2008), wherein the 'half-second' delay is identified as a way of distinguishing between some deep sense lurking inside us (affect) and its identification as a feeling or emotion, especially when triggered by an interaction with the world around us.

There are considerable debates on how the relationship between affect and emotions can be understood (Pile, 2010). One line of argument suggests that emotions are expressible and graspable, whereas affects are impossible to represent, given their specifically pre-conscious nature (Conradson, 2005a; Thrift, 2008). Pile (2010: 9) cites Anderson (2006), in describing affect, feelings and emotions as a series of layers, in turn non-cognitive, pre-cognitive and cognitive. While the non-cognitive might be identifiable as a sort of 'stored' affect, the pre-cognitive identifies intuitive elements that lie between affect and emotion while the cognitive is seen as expressed emotion. An alternative argument takes issue with the splitting off of these elements in favour of a more unbounded and continuous emotional geography framed by use and context (Bondi and Davidson, 2011). Bondi and Davidson argue persuasively that a more productive route is to consider affect, feeling and emotion as continuous elements, rather than separating them out from one another. This tallies with Spinney's more open definition above, especially the identification of affects that emerge through relational encounters. This paper similarly takes a continuum approach to how affect and emotion might shape how health is produced in place and considers both theory and practice in tandem.

When applied to emotional geographies, there are potential positive and negative experiences that run from the instinctive and inexpressible elements of affect - both non- and pre-cognitive -to more cognitive elements - feeling, moods, urges, reactions, intentions (Anderson, 2006). There is a space for all of these within a theoretical model that is open to movement along a spectrum; they are different yet connected through bodies and wider material assemblages, even if that connectivity is often blurred and indistinct. . A continuum approach draws from a more experiential and enacted perspective; citing Kobayashi, et al., (2011: 873) who:

"see the process of experiencing affect as a cumulative, and therefore historical, process of interaction between human beings and place (including other human beings) through which the capacity for individual feelings arises. In other words ... affect is always contextual; therein lies its value for geographers who study place".

Of special interest is the idea of the cumulative, which will be revisited below. For Simonsen (2012), citing the work of MerleauPonty, such a 'non-dichotomous' approach, cuts through distinctions between affect and emotion and sees them as a blending together of inner and outer relations with the world. The affective and emotional continuum contains both the 'expressive space' of bodily movement and the 'affective space', that opens up bodies to the world. Given that affect and emotion are central to writing on non-representational theory (Thrift, 2008), the hard-to-explain parts are often described in specifically performative and embodied ways - dancing or cycling - that highlight expressive embodied elements. Spinney 2006 account of cycling up Mont Ventoux effectively captures affect through describing kinaesthetic practice and emergent affects/emotions linked to the site's contextual history; apprehension; the communitas of fellowcyclists; physical pain, the hot sun, the laboured pedal-stroke and surges of effort and will that combines into a set of actions that, at their completion, produce a profound feeling of wellbeing and achievement.

Used here with specific reference to the healthy act of swimming (Foley, 2015), an affective and emotional continuum emerges from repeated individual and communal embodied and emotional acts, portray swimmers as complex active subjects and blue space environments as affective settings. Swimming places are permeable spaces that produce permeable responses that cross over between affect and action. Macpherson (2010:5) notes that:

“... our actions and conscious thoughts in any given environment may be the result of pre-conscious thought shaped by the technologies and objects available; and the contexts and cues of a particular landscape. So objects available and physical landscape contexts are implicated in what the body is and what the body is likely to do in any given moment".

These (therapeutic) landscape cues and associated intentions matter, especially for applied medical/health geography; as active and embodied end-points along the affective and emotional continuum.

\subsection{Active and passive therapeutic geographies}

Concerns with activity are evident in recent studies on healthy living and human movement. Typically these are driven by public health concerns over sedentary lifestyles and the rise in obesity; as seen in a range of studies on green space, active living and the planning of healthy environments to improve health outcomes (Mitchell, 2013; Richardson et al., 2013). In contrast, affective and emotional concerns are central to recent research on therapeutic landscapes, combining both physical and mental health (Bingley, 2003; Conradson, 2005b). Duff (2012) argues persuasively that the role of place in producing affect (and vice-versa) is under- 
estimated and this has special relevance to the study of healthy environments. Place becomes an active subject rather than a passive object in such settings and it is the combination of peopleplace interactions and the specific qualities of the environment that work together to enhance health.

Suggesting that a wider affective and emotional health emerges from place also reflects therapeutic landscapes research on everyday spaces and practices that exemplify a, 'healing process working itself out in place' (Gesler, 1992). Here health outcomes are increasingly unpredictable and drawn from personal experience, shaped by what Conradson describes as, “... as a positive physiological and psychological outcome deriving from a person's imbrications within a particular socio-natural material setting" (Conradson, 2005b: 339). Such imbrications can be active, through physical activity, yet equally passive, as reflective and imaginative experiences of place. When applied specifically to swimming environments, such imbrications can be seen as physical and emotional immersions with (in) the water. That immersive therapeutic aspect of swimming is central to both the physical act and more contemplative blue space experience.

Conradson (2005b) however, suggests that imbrications in place also have the capacity to engender multiple health outcomes. These tensions have been documented in green/blue space studies of woodlands, gardens, beaches, waves and islands. While woodlands for example were associated with improved wellbeing and a health derived from nature, for other users, they were dark and dangerous settings (Milligan and Bingley, 2007). Beaches are felicitous spaces (Game and Metcalfe, 2011), sites of contested embodiments and social practices (Lobo, 2014) yet perversely, the simultaneous setting for both healthy exercise and drownings/melanomas (Collins and Kearns, 2007). Blue space activities such as surfing equally open up bodies to both life-enhancing and life-threatening experiences (Anderson, 2014; Evers, 2009). The benefits to ageing in blue space, especially islands, is also identified as providing an affective connection to nature, though again tempered by aspects of isolation and reduced physical access (Coleman and Kearns, 2015).

\subsection{Therapeutic accretions}

In bringing together the idea of an affective and emotional continuum with active/passive therapeutic geographies, this paper argues that swimming provides a useful empirical model for how therapeutic accretion works. Straughan's work on diving acts as a valuable guide, in its concern with emotional and embodied wellbeing within deep blue space. Here bodies in motion are, "shown to be comprised of an incessant 'layering of and 'adding to' embodied experience, which in turn mobilize(d) a particular complex of emotions" (Straughan, 2012: 20). Straughan use of the term 'layerings' might be usefully contrasted with 'fleeting', a word often used in emotional/affective geographies. Thrift (2008) identifies the importance of fleeting aspects of experience that Spinney (2015) suggests sometimes leave little 'trace'. Yet Lorimer $(2005,84)$ notes that:

"(healthy) life takes shape and gains expression in shared experiences, everyday routines, fleeting encounters, embodied movements, precognitive triggers, practical skills, affective intensities, enduring urges ...".

It is precisely the ways in which the fleeting accumulates across routine, everyday, sedimented and affective encounters that produces a therapeutic accretion. These repeated encounters run through people's lives as, "ongoing mapping(s) of space through repetitive, collective choreographies of congregation, interaction, rest and relaxation (that) produce situated rhythms" (Edensor, 2010: 8) and, I would argue, a deepening of health and wellbeing.

Employing the term accretion draws from maritime metaphors. If we consider metals under-water - anchors, chains, the Titanic we envisage them as encrusted objects, with various maritime materials building up on them over time. Equally, I argue that can we see swimming as a therapeutic accretion, wherein body knowledge, memory, practice and place encounters build to develop a resilient wellbeing. The metaphor is not perfect. It is for example, possible to chip this material off, while the physical act of drying oneself down outside of the water equally washes off some of that crust. Yet, as a metaphor, the mobile crust protects and provides resilience in psychological and affective ways. Another way to think about accretion is the way in which a pearl oyster evolves; nacre built up as a series of layers over a small piece of grit; yet simultaneously the lacquer-like layering on the inside of the shell itself. Therapeutic accretion works in a similarly backwards and forwards way. If a resilient crust is built up with every swim we take, this helps sustain our health in a forward direction; yet the experience of the swim is also an echo backwards along the emotional continuum to an affective past where that deep initial layering took place. Putting these together, the fleeting event of the swim and the milieu in which it takes place, harden into a sort of embodied lacquer of wellness.

In arguing for an accretion of therapeutic benefits from swimming, attention should also be paid to both active swimming lives and more passive and reflective aspects of relational encounters within therapeutic landscape. This echoes older phenomenological work on dwelling and newer writing on stillness (Ingold, 2000; Conradson, 2005b). Thus accretions - or as Thrift would have it, 'concretions' - emerge as part of a relational continuum as one accesses such resources backwards and forwards through healthy (swimming) lives; the repeated activities and indeed the water itself, always reflect interplays between movement and stillness (Duff, 2011). The research suggests that such immersive practices lead to a form of accretional health, built up over time and developing both physical and mental health resilience. For swimmers, place-based accretions and imbrications, involving both short-term 'dippings-in' and longer-term absorptions, help shape a range of layered resonant encounters and shared emotional memories that enable and support human wellbeing (Conradson, 2005b; Duff, 2010; Straughan, 2012).

\section{Studying swimming spaces}

The work draws from outdoor swimming locations in Ireland, both coastal and inland. With average summer water temperatures rarely exceeding fifteen degrees celsius, swimming in Ireland takes a certain level of hardiness and this shaped responses, depending on whether one was an occasional or year-round swimmer. The study used mixed methods, primarily oral history interviews, (auto)ethnographic work including swimming diaries, observer participation and video. Detailed work was carried out at three core coastal sites (Fig. 1a, b and 1c), the 40 Foot (on Dublin Bay), the Guillemene (near Tramore, County Waterford) and The Pollock Holes (in Kilkee, County Clare). Each site had established swimming histories going back at least a century (Foley, 2010). Each had a large number of all-year round swimmers, who formed the bulk of the interviewees.

Given Duff (2012) concern for how places become therapeutic, I was interested in swimmers' voices, hence the choice of an oral history approach. Twenty swimmers were interviewed about their swimming lives, and were primarily chosen for a sustained history of swimming in particular locations. Their ages ranged from the late $30 \mathrm{~s}$ to late $80 \mathrm{~s}$, opening up the potential of exploring the idea of an accreted health that might not have been so evident in younger 

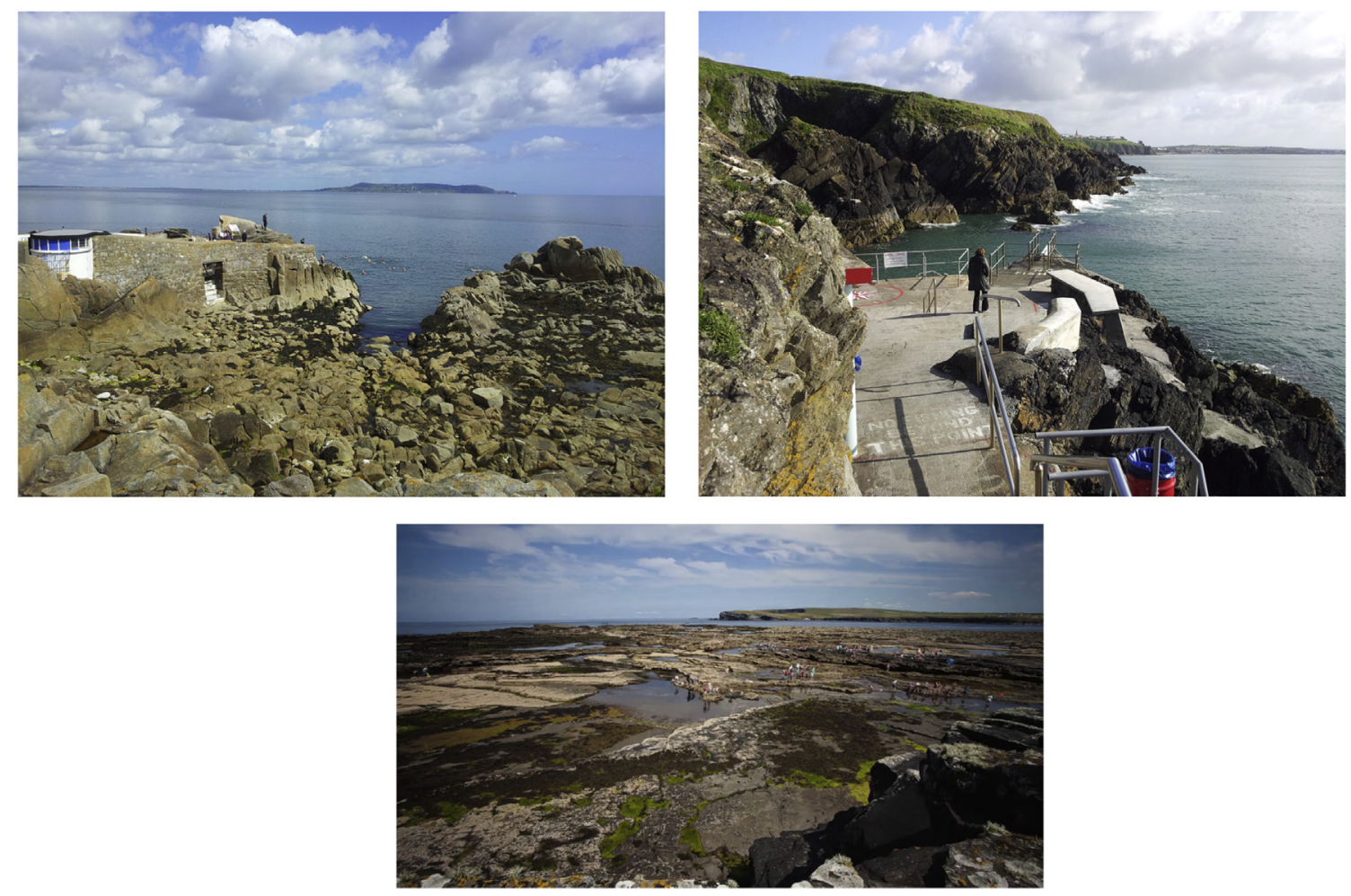

Fig. 1. Study Sites: The 40 Foot, The Guillemene, The Pollock Holes (l. to r.).

swimmers. Women formed around $60 \%$ and were spread relatively evenly across the sites. Interviews mostly took place away from the swimming spots, but some were carried out in-situ beside the water. Interviews were transcribed and analysed using MaxQDA and several key themes emerged including family, embodied response and place specific practices. The author's personal swimming diaries covered two years (2013-15), based on hourly visits at different times of the day and year at all three sites. These diaries combined personal thoughts, experiences and site observations, while short videos, taken by the author, enhanced the observation and consideration of swimming practices.

Very broad questions were used as prompts to establish swimmers' early swimming histories and current practices, followed by questions about emotional and embodied responses to being in and around the water. Taking an oral history approach meant that (dis)continuous traces of personal swimming histories and emotional attachments to individual swimming places, emerged from those conversations (Perks and Thompson, 2006). It tracked individual voices over time, but also the interplay of personal/collective encounters across time and space. In capturing accounts from different locations of open-air swimming, there were overlaps, immersions, place-specific and contested accounts that produced an assemblage of place narrative. Accounts often contradicted one another, or varied by individual experience that reflected the idea of differential imbrications. Rather than single 'here and now' accounts, several 'here's and now's' and 'there's and then's' accounts were used to show how a contemporary dinnseanchas (a traditional Irish term for narratives and legends about very specific local places) emerged. How those narratives uncovered aspects of health and wellbeing was also central to the methodological thinking. The questions on health/wellbeing were open-ended, to uncover subtle and under-understood dimensions of individual and communal health from the respondents, incorporating affective and enabling aspects of place.

\section{Swimming stories: Therapeutic accretions in Irish waters}

\subsection{Accretive practices}

The pre-requisites for good outdoor swimming spots are depth and movement. The 40 Foot and Guillemene are swimmable at all tides, while the Pollock Holes are more contingent, being inaccessible at high tide. Counter-dimensions of space - shallowness and stillness - also shaped how therapeutic accretions were developed, through paddling and floating. Several swimmers referred to getting 'stuck' into the regular act of swimming, and habit had an enduring impact. Yet there were other narratives; breast cancer survivors who took up swimming late in life; irregular swimmers who literally dipped in and out at various points in their lives when one was in the right place, literally and emotionally, to do so. While elements of risk and tragedy were noted, most narratives suggested a positive healthy outcome to their accretive practices.

As respondents recounted their swimming histories, common narratives emerged. In the interplay of memory, different life moments - early childhood, teenage years, adulthood and older age were identified from different locations, within which more-thanemotional elements featured strongly. In describing where the respondents first remembered swimming, how they learnt and who with, there were deep echoes of families, friends and places. Equally, there was an implicit health dimension to those swimming stories. Many talked about swimming as children and teenagers, often a hiatus in their early adult years, but a return to the water in later life; a lifelong rhythm that varied with the different places that people swim or swam in across their lives (Edensor, 2010). From a range of locations, embedded connections to those swimming places are central to emotional histories (Game and Metcalfe, 2011). For Respondent Y, swimming had an unconscious dimension learnt along the way that reflected a sensuous affective response embodied in both place and practice. That emotional response was 
also specifically attuned to blue spaces.

It's probably changed in the way ... as a kid you don't think about swimming, you just get into the water and enjoy splashing in the water and you become a teenager and it's a different thing as well cause you're with your friends ... I think being near the sea is what it has to do with ... like some people like to smell mountains or woods or forests if they've grown up inland ... (but) the smell of the sea, the smell of decaying seaweed that everyone gives out about ... that is so attractive to someone who's always lived by the sea ... that's something that is with you all of your life. I dunno if my attitudes changed, it's just always been there and you take it for granted I suppose. (Respondent Y. 40 Foot)

Most respondents talked about learning to swim with family or friends, often in unusual ways via organic, almost osmotic learning processes. In both cases below, a removal of layers (of floatation supports) was arguably balanced by the addition of new layers of embodied knowledge and experience.

The first place I remember swimming was the first Pollock hole in Kilkee ... we started at an age, probably 6 or so, it was such an achievement to swim across the first Pollock hole ... our swimming aid would have been an old black tyre, that was thrown in to the Pollock Hole and you went in with it to get across and back ... in the end you didn't need the swimming tyre but there was no such thing as swimming lessons. (Respondent E, Kilkee)

I grew up swimming in the River Dinan outside Kilkenny in the late 1940s. The local swimming learning was based on starting out with twenty reeds tied around the body and then slowly removing the reeds each time you swam. It was taken that once the last reed was removed you knew how to swim. (Respondent $\mathrm{MB}$, Nore/Dinan)

In later life, the practice of swimming as maintainer and restorer of health (re)emerged; described by one Guillemene respondent as a 'a regular shower of wellness', or by a 40 Footer keen to use swimming to rediscover fitness as a 'getting back to health'. Sometimes, swimming in cold water threatened health as well, through catching cold or hypothermia or, for one Guillemene swimmer, being told not to swim for fear of catching infection from the water, echoing wider environmental health concerns (Collins and Kearns, 2007).

Viewing health as both an emotional and embodied process, other accretive rhythms emerged; from chronic to acute or repeated chronic illnesses, including soft tissue injuries and arthritic conditions, which were managed through swimming for a wide range of bodies; large and small, healthy and unhealthy. Many older swimmers saw swimming as a way of managing (ill-) health and alleviating symptoms beyond conventional medication.

It's good exercise and it's probably one of the most beneficial in the sense that you're not putting any strain on your joints you know ... and I have arthritis but I don't blame swimming for that ... But even if swimming was the cause of it, I'd say to hell with it you know. I feel the exercise has to be beneficial. You know my wife often says to me, she doesn't know anyone my age that isn't on a stick. (Respondent E, Guillemene).

I love to get in because I have, I haven't, I suppose it is oncoming arthritis, and I do really feel that the swimming has hugely helped my shoulders. In the past two years I've had a problem, particularly with my right shoulder and I've had steroid injections and it has helped, but you can't continue with that. (Respondent E, Kilkee).

For older people especially, the ability to do some sort of rhythmic exercise, with low impacts on brittle bones or chronic bodily pain, saw swimming as a rare form of active treatment, best exemplified in the pithy but powerful comment, 'The only time I don't limp is when I'm in the water'. (Respondent MM, 40 Foot). A more specific emotional journey was evident in the case of a husband caring for his wife who had multiple sclerosis.

There was a woman who had multiple sclerosis who used to come down and her great thing was to swim with her husband. He'd wheel her down in her wheelchair ... and he used to wheel her down every single day ... and it kept her absolutely feeling that ... doing something in the water was life for her really movement - she could swim or she could stay afloat with little movements that she couldn't do in the wheelchair. (Respondent C. 40 Foot)

A significant therapeutic resilience emerged from this account, incorporating the physical sense of enabling a movement not possible on land, but also enabling an unhealthy body in a healthy way. From an emotional perspective, that sense of 'staying afloat' had wider transformative meaning, in being able to escape one's confinements to maintain a bodily capacity, but also through a remembered past in which the power of the blue space memory, physical and imaginative, enabled health in that space (Sherr, 2012).

Swimming was also identified as important to illness recovery with anecdotal reference to breast cancer, wherein rebuilding the weakened upper-body through swimming is considered a model treatment (Pittinger and Graves, 2013). Even the prospect of a sudden death in the water seemed not to concern some swimmers.

I have a friend who tells me I'm mad to be swimming you know; in the winter ... you could get a heart attack. But my answer has always been, 'well out in the Guillemene I'd just be going from one heaven to another'. (Respondent E, Guillemene).

\subsection{Resonant encounters}

The affective and emotional continuum was equally evident in resonant encounters identified by swimmers. These included place-specific encounters contributing to wellbeing, before, during and after a swim. In asking why swimmers swam, how it affected them and how they felt in the water, many responses referred to affects, feelings and expressed emotions, but also to specific practices from which those responses emerged. Immediate embodied and emotional responses complemented longer term experiences wherein daily swims formed an accumulation of 'fleeting traces';

I suppose when you are swimming, when you are out in the sea, in the ocean you know, there's nothing else there and you really connected with nature ... and they're beautiful stunning spots ... you swim out maybe five hundred yards from the beach ... look back at the cliffs and the fields and the mountains and shoreline ... it's an amazing experience and you obviously have that nice cold shock as well, gets every sensation in your body going ... you feel really alive and you also feel connected I think to the Universe and connected to family. (Respondent $\mathrm{R}$, Guillemene). 
Connections with nature were important aspects of place responses as the respondent above described becoming literally part of nature, detached and reversed in a sense from the traditional 'blue' landscape view from land, yet affectively expressed in embodied even spiritual ways (Anderson, 2013). From observations at all three sites, teenage boys embodied that first discovery of nature and the sheer unadulterated joy of jumping in and letting go. Such (almost clichéd) mid-air jumping images were in one sense the ultimate affective moment. But rather than just a single moment in mid-air, it was the moment just before the jump, the chilling gasp as you hit the water and the vigorous thrashing about once in it, that better illustrated the continuum idea. There was something primal (even non-cognitive) about the urge to enter the water - the breaking of a surface that, as Sherr (2012), noted, closed behind you - that led sometimes to an almost other-worldly experience, where varied palettes of place became visible.

When I dive in the water and I open my eyes, it's like when Judy Garland in Over the Rainbow ... it's like when she opens the door or whatever or she wakes up, and the film goes from black and white to colour ... it depends you see on the day ... the water could be brown, it could be aquamarine, it could be green, it could be vivid blue, it could be ... if the sea is agitated it could have sparkle. There's so many different colours and it's always a wonder to know ... well it isn't a wonder so much as a surprise when you open your eyes before you come up and ... whether we all came out of the sea or all crawled out of the sea or not I dunno, but certainly there's some kind of a personal rapport or wonderment to the colours (Respondent E, Guillemene).

In describing swims as repeated micro-events, there are complex emotions and feelings involved, some as above, reflecting deeply embodied and pre-cognitive senses, but also suggestive of emotion (agitation) implicit in the place (water) itself. In contemplating going for a swim, especially when faced with very cold water on a miserable day, there were a series of experiential choices to be made and after-affects to recount. Several swimmers talked about preparing to swim, an often quick dip described variously as '8 out, 10 back' or 'teabag' swimming explicitly shaped by the temperature and swell of cold Irish water and the sense of satisfaction and warming up after a swim, knowing it was good for you. For many, the experience of the swim, rather than its length, was what mattered, something different to the standard experience of indoor swimming. Outdoor swimming changed with the seasons and for long-distance (LDS) or competitive swimmers, thin wetsuits allowed for longer immersions.

Obviously the length of swim varies ... in the summer I can stay in the water for up to an hour ... this is still June ... so you could stay in the water for about half an hour .... in winter I'd be lucky if I had 60 seconds in the water ... the exercise is in getting dressed and undressed I think (laughs) more than the swim ... (so you don't make a distinction between different experiences, a quick dip or long swim?) ... No, because I think they change with the seasons, it's a gradual thing and ... you can have a swim as opposed to a dip up till Christmas and then usually January and February are the coldest months for swimmers ... I mean the water is quite cold until May ... so the middle times it's teabag swimming ... (Respondent Y. 40 Foot).

I feel, once there's a chill that makes it. There has to be a chill to make you feel good and you dive in and there has to be a chill ... (Respondent MM, 40 Foot).

Once in the water, a place affect emerged from the emotions and experiences of being there, where wellbeing came, as one respondent noted, from being in a place where 'everything goes ... you're lost in the sheer pleasure ... where 'nothing matters and it's a little blip (in a good way) in your life'. Being in the water worked as a means of emplacing oneself outside the flow of everyday life; described in some accounts as though pressing a reset button (Straughan, 2012). One competitive LDS swimmer noted 'zen' moments, in part brought on by apoxia (oxygen deficiency) because of the durational intensity. Respect for the power of the water echoes Evers (2009) comments on the dangers of other blue space experiences such as a surfing wipeout. Swimming is always potentially dangerous and unhealthy. One respondent, when asked about the potential dangers of swimming noted a personal agency to her swimming choices (Bell et al., 2014);

Sometimes if you are against a current it's very interesting to challenge yourself ... and I think that can be important too ... where we swim in Sandycove/40 Foot that area, there are quite strong currents ... and if you go with the flow you can cover a distance in three minutes ... if you go against the flow that could take you 40 minutes to do against the flow. In summer when I am reasonably fit I quite like the challenge of working against the flow ... course you know the thing is lots of people try swimming against the flow and forget that they can turn back if they can't make it. (Respondent Y. 40 Foot).

For almost all regular swimmers, the thought of not going for a swim on a daily basis affected health and wellbeing. Various respondents' mentioned a sense of duty but equally, unease from not swimming. This was felt as an emotional loss of both wellbeing and the regular enactment of embodied rhythms. In learning as a child to open oneself up to the water, one also opened one's body and emotions to blue space as well. This could be lost across the lifecourse but a regular commitment to swimming meant that by definition, one moved one's body and gaining a physical benefit from it, no matter the age. As swimming became habitual practice, many swimmers recounted it as a need/compulsion, even as a form of combined physical/emotional addiction that emphasised place attachment, but also freedom from everyday cares and worries.

If you miss the swim, you're miserable, you feel there's something not right ... and you're moaning and moaning but I feel now as if I could walk up the mountain, no problem, because of the swim. (Respondent MM, 40 Foot).

Also when I swim I feel liberated, a bit like a fish I feel free and there's peace and quiet both physically and mentally, you can relax in the water or away on a boat, even under the water surrounded by crustaceans. (Respondent ML, Kilkee).

For several respondents, describing their swimming lives reflected more-than-emotional family histories and moments of trauma and loss.

There's a whole load of emotions that are connected and memories connected with swimming and the space ... it's such an experience you know, a whole body experience that it probably does capture things, connect things more ... I would have lost my Dad when I was 20, he died and you know that was quite a traumatic time ... he was 56 and he died from a brain tumour ... surfing and swimming was always a way the family connected ... and it was an activity that we would have done together ... you know we still do that ... go for swims together, we meet up and you know, go for a swim on the beach on Kilfarassey beach ... so it's a nice way to connect and it is different 
and I feel at times connected with my Dad as well. (Respondent $\mathrm{R}$, Guillemene).

In this and others cases, personal histories of swimming helped them come to terms with loss, expressed through a physical act that helped fix emotional health connections in time and space. In conversation, many respondents expressed a mood of nostalgia but also a brightened memory. While difficult to capture, almost all smiled when answering many of the questions about the past, perhaps reflecting a triggered sense of 'memory therapy' found in other blue space settings (Coleman and Kearns, 2015).

\section{Discussion: health from sedimented swimming encounters}

Evidence for a therapeutic accretion emerged from swimmers' accounts of how their own encounters with the water helped build resilience in the maintenance and recovery of health. The resonance of those encounters are linked to the physical act of swimming in the open sea, with the people one swam with and with the swimming places themselves, where habits and companionship support Macpherson (2010: 6) assertion that, "the regular performance of particular embodied roles results in them becoming a habitual and neurologically sedimented phenomenon". While the level of activity in the water varied by age and bodily condition, it was also shaped by the physical mobility of the sea-water, rarely calm in Irish waters. The embodied adaption to the conditions, the cold and the state of one's own body all shaped how an accretion of physical health developed.

In seeing swimming as a continuous affective and emotional practice, more passive elements of affect, feeling and mood were also braided within it. Together they co-produced an embodied and emotional therapeutic accretion. As several of the respondents noted, and in my own observer participations, mood and mental state shaped the key decision to 'go in for dip'. Space does not allow for a full description, but as a swimmer, there was a natural continuum from the urge/instinct (affectively embodied. mood dependent) to go for a swim, the smell of the swell and the building excitement/apprehension as the water came in to view (affectively/ emotionally sensed and accessing a stirred body memory), the shared experience of undressing and entering the water (mixed emotions of remembered coldness and preparing the body for the water) and the strange noises emitted during and after the swim (as expressed emotion and body-shock).

It is important though, to note other dimensions of the swimming experience, where risk and joy can be simultaneous outcomes (Collins and Kearns, 2007). In such moments, depletions as well as accretions of health can occur. Most respondents were very respectful of the power of the sea and indeed for some, an underlying affective fear of the sea sustained that respect. But the majority focused on its more positive value across the life-course and the building up, especially for older regular swimmers, of a literal physical resilience, a natural outer layer (most eschewed wetsuits) absorbed through their regular cold-water immersions and reflected in physiological tests (Sherr, 2012). While there were some judgmental comments on the risky behavior of the youthful divers, older swimmers, 'who should know better' were also identified as disregarding their own, and at times, others safety. Given known associations between rivers and suicide (Peden et al., 2016), the breaking of the water referred to by Sherr (2012) may equally see broken water closing behind people in more definitive ways.

All swimmers have bodies with varying physical and emotional capacities. Such 'multiple' dimensionalities of the body are central to how swimming enables health in different ways and draw attention to a public health value for research. The initial quote by
Sherr invoked swimming as stretching earthly limits and indeed the land-bound capacities of older or disabled bodies become very different in the water. In entering the water, the swimmer literally shifts from being a subject to becoming a co-subject within the object and indeed, given the difficulties in breathing in choppy seas, often swallows and absorbs the water into their own bodies such that the object permeates the subject (Straughan, 2012). Similarly an inter-subjectivity emerges from the accretive process, through memories of swimming experiences, shared with family, friends and even complete strangers that is deepened by what Duff (2011) considers place affects. In inter-generational encounters, a sense of place is built up over time reflecting not just individual, but also overlapping and shared affects, spread across different generations and bodies. That shared sense of resonance in turn produces a thick (deep) place and experience that is co-produced through accretions across time and place (Edensor, 2010).

The cases of the woman with multiple sclerosis or older men with walking-sticks, spoke to a deep transformative potential for blue space. In providing a shared space for all bodily sizes, shapes, genders and ages, the swimming spots operated differently to more public spaces of display such as the beach. Indeed Throsby (2013), notes that being overweight is a positive advantage for longdistance and endurance swimming. There were clear overlaps, but the focus on the act of swimming and specific changes in bodily potential created in the water, acted as important components of health promotion and suggest some new directions for public health. All of the spaces were open, democratic and intergenerational and created healthy places for all. Yet it is important to be realistic. Health effects/affects that build up across the life course can atrophy and ageing does reduce the ability to actively swim; equally it is important to acknowledge the fact that water can disable human movement as well as enable it.

Given that public health is generally focused on indoor swimming, such insights might be more fully utilised in health policy terms (Parr, 2011). It could focus health promotion attention onto more nuanced understandings of individual bodily capacities there is no such thing as a 'standard swimmer'- and natural settings for exercise and wellbeing (Foley, 2015). One important recommendation might be to 'value' outdoor swimming places more fully and provide the same level of safety training as occurs in indoor pools. By drawing on the experience of older swimmers, it might also be a way to value their insights and local place knowledges as well.

\section{Conclusion: swimming bodies, emotions and practices}

This paper has drawn from different outdoor swimming informants and locations in Ireland to further extend the idea of an affect-emotions continuum and utilise that framework to develop the idea of a therapeutically accretive practice. The swimming spots and the water in them would be considered cool in global terms and such contextual factors framed swimming as a committed 'healthy act' drawn from an emotional geography expressed through relationships; with place, with family, with others. Employing the construct of an affective/emotional continuum, can be reimagined as a temporal process, to move from single individual 'zen' moments into a wider set of multiple repeated practices, emergent in time and space (Spinney, 2006). A methodological focus on oral history used accounts from different settings and informant life-stages to uncover both ineffable and directly articulated evidence of health benefits linked to swimming.

Different dimensions of place also enabled healthy emotional and affective life. Many swimmers' accounts reflected how different experiences, affects and even health outcomes were contingently shaped by the 'dimensionality' of the swimming spaces themselves. 
This referred not only to shared narratives of particular places, but also resonant encounters in and out of the water that specifically reflected different types of water environments - rocky, sandy, tidal, lacustrine, riverine, and artificial - within which that swimming took place. It also reflects the importance of rhythms - the relational encounters of and between people and places - in creating health and wellbeing in such blue space settings (Edensor, 2010; Duff, 2011). Connections between land and sea-bodies were essential to the process of therapeutic accretion. The same respondent, who referred to being at one with the crustaceans, also noted that, 'It's nice to come out of the sea with your body covered in salt'. For most humans, swimming supplements the saline crust already within us (Hoare, 2013). There were both liminal and permeable dimensions in swimming encounters that exposed bodies to danger and indeed to other elements in the water. Though not explicitly discussed, many more-than-human elements were present, including; tides, boats, seaweed, seals, jellyfish, wetsuits and even changing built environments over time. All of these shaped the memories and experiences of swimming and might be usefully studied in more detail.

There is considerable scope to develop future work through a range of swimming spaces (including indoors and private settings) and swimming bodies (Foley and Kistemann, 2015). In further exploring relationships between blue space, embodiment and physical heath, numerous recreational health pursuits - floating, snorkelling, diving, kayaking, surfing, rowing and sailing increasingly use innovative methodologies (Go-pro cameras, waterproof sound recorders) to capture more-than-emotional geographies in place and uncover in-situ experiential narratives (Merchant, 2011; Bell et al., 2015; Brown and Humberstone, 2015). Balancing the more positive focus of such work, other research agendas that consider unhealthy aspects of blue space are equally necessary. Groups who can't, won't or don't swim may provide an additional reflexive/contested aspect as well as a putative control group. Here, more (aqua)phobic responses to water emerge (Lengen, 2015). Straughan (2012) notes that water could be destabilising in a kinaesthetic sense, yet ironically one swimmer noted that at times of stress, 'when it feels like there no solid ground to put your foot down, the sea is that for me' (Respondent R. Guillemene). Overall, the value of swimming as an accretive therapeutic practice, continues to enable health and wellbeing in its practitioners and in resilient places that continue to provide an ongoing public good.

\section{References}

Anderson, B., 2006. Becoming and being hopeful: towards a theory of affect. Environ. Plan. D Soc. Space 24, 733-752.

Anderson, J., 2013. Cathedrals of the surf zone: regulating access to a space of spirituality. Soc. Cult. Geogr. 14 (8), 954-972.

Anderson, J., 2014. Exploring the space between words and meaning: understanding the relational sensibility of surf spaces. Emot. Space Soc. 10, 27-34.

Anderson, J., Peters, K., 2014. Water Worlds: Human Geographies of the Ocean. Ashgate, Farnham.

Bell, S., Phoenix, C., Lovell, R., Wheeler, B., 2014. Green space, health and wellbeing: making space for individual agency. Health \& Place 30, 287-292.

Bell, S., Phoenix, C., Lovell, R., Wheeler, B., 2015. Using GPS and geo-narratives: a methodological approach for understanding and situating everyday green space encounters. Area 47 (1), 88-96.

Bingley, A.F., 2003. In here and out there: sensations between self and landscape. Soc. Cult. Geogr. 4 (3), 329-345.

Bondi, L., Davidson, J., 2011. Lost in translation. TIBG 36 (4), 595-598.

Brown, M., Humberstone, B. (Eds.), 2015. Introduction, Seascapes: Shaped by the Sea. Ashgate, Farnham.

Coleman, T., Kearns, R., 2015. The role of bluespaces in experiencing place, aging and wellbeing: insights from Waiheke Island, New Zealand. Health \& Place 35, 206-217.

Collins, D., Kearns, R., 2007. Ambiguous landscapes: sun, risk and recreation on New Zealand beaches. In: Williams, A. (Ed.), Therapeutic Landscapes. Ashgate, Farnham, pp. 15-32.
Conradson, D., 2005a. Freedom, space and perspective: moving encounters with other ecologies. In: Davidson, J., Bondi, L., Smith, M. (Eds.), Emotional Geographies. Ashgate, Aldershot, pp. 103-116.

Conradson, D., 2005b. Landscape, care and the relational self: therapeutic encounters in rural England. Health \& Place 11, 337-378.

Davidson, J., Bondi, L., Smith, M. (Eds.), 2005. Emotional Geographies. Ashgate, Aldershot.

Deakin, R., 1999. Waterlog. A Swimmers' Journey through Britain. Chatto \& Windus, London.

Duff, C., 2010. On the role of affect and practice in the production of place. Environ. Plan. D 28 (5), 881-895.

Duff, C., 2011. Networks, resources and agencies: on the character and production of enabling places. Health \& Place 17, 149-156.

Duff, C., 2012. Exploring the role of 'enabling places' in promoting recovery from mental illness. a qualitative test of a relational model. Health \& Place 18, $1388-1395$.

Edensor, T. (Ed.), 2010. Geographies of Rhythm. Nature, Place, Mobilities and Bodies. Ashgate, Aldershot.

Evers, C., 2009. 'The Point': surfing, geography and a sensual life of men and masculinity on the Gold Coast, Australia. Soc. Cult. Geogr. 10 (8), 893-908.

Foley, R., 2010. Healing Waters: Therapeutic Landscapes in Historic and Contemporary Ireland. Ashgate, Aldershot.

Foley, R., 2015. Swimming in Ireland: immersions in therapeutic blue space. Health \& Place $35,218-225$

Foley, R., Kistemann, T., 2015. Blue space geographies: enabling health in place. Health \& Place $35,157-165$.

Game, A., Metcalfe, A., 2011. 'My corner of the world': bachelard and bondi beach. Emot. Space Soc. 4, 42-50.

Gesler, W., 1992. Therapeutic landscapes: medical issues in light of the new cultural geography. Soc. Sci. Med. 34, 735-746.

Hartig, T., Mitchell, R., de Vries, S., Frumkin, H., 2015. Nature and health. Annu. Rev. Public Health 35, 207-228.

Hoare, P., 2013. The Sea Inside. Fourth Estate, London.

Ingold, T., 2000. The Perception of the Environment: Essays on Livelihood, Dwelling and Skill. Routledge, London.

Kaplan, R., 1995. The restorative benefits of nature: toward an integrative framework. J. Environ. Psychol. 15, 169-182.

Kobayashi, A., Preston, V., Murnaghan, A.-M., 2011. Place, affect, and transnationalism through the voices of Hong Kong immigrants to Canada. Soc. Cult. Geogr. 12 (8), 871-888.

Lengen, C., 2015. The effects of colours, shapes and boundaries of landscapes on perception, emotion and mentalising processes promoting health and wellbeing. Health \& Place 35, 166-177.

Lobo, M., 2014. Affective energies: sensory bodies on the beach in Darwin, Australia. Emot. Space Soc. 12, 101-109.

Lorimer, H., 2005. Cultural geography: the busyness of being 'more-than-representational'. Prog. Hum. Geogr. 29 (1), 83-94.

Macpherson, H., 2010. Non-representational approaches to body-landscape relations. Geogr. Compass 4 (1), 1-13.

Merchant, S., 2011. The body and the senses: visual methods, videography and the submarine sensorium. Body Soc. 17 (1), 53-72.

Milligan, C., Bingley, A., 2007. Restorative places or scary spaces? the impact of woodland on the mental well-being of young adults. Health \& Place 13, 799-811.

Mitchell, R., 2013. Is physical activity in natural environments better for mental health than physical activity in other environments? Soc. Sci. Med. 91, 130-134.

Parr, H., Davidson, J., 2010. Mental and emotional health. In: Brown, T., McLafferty, S., Moon, G. (Eds.), Handbook of Health and Medical Geography. Sage, London, pp. 258-277.

Parr, S., 2011. The Story of Swimming. Dewi Lewis, Stockport.

Peden, A., Franklin, R., Leggat, P., 2016. Fatal river drowning: the identification of research gaps through a systematic literature review. Inj. Prev. 22 (3), 202-209.

Perks, R., Thompson, A. (Eds.), 2006. The Oral History Reader, second ed. Routledge, London.

Pile, S., 2010. Emotions and affect in recent human geography. TIBG 35, 5-20.

Pitt, H., 2014. Therapeutic experiences of community gardens: putting flow in its place. Health \& Place 27, 84-91.

Pittinger, E., Graves, S., 2013. Swimming as exercise prescription for breast cancer patients. Strength \& Cond. J. 35 (6), 46-53.

Richardson, E.A., Pearce, J., Mitchell, R., Kingham, S., 2013. The role of physical activity in the relationship between urban green space and health. Public Health $127,318-324$.

Ryan, A., 2012. Where Land Meets Sea: Coastal Explorations of Landscape, Representation and Spatial Experience. Ashgate, Farnham.

Sherr, L., 2012. Swim. Why We Love the Water. Public Affairs, New York.

Simonsen, K., 2012. In quest of a new humanism: embodiment, experience and phenomenology as critical geography. Prog. Hum. Geogr. 37 (1), 10-26.

Spinney, J., 2006. A place of sense: a kinaesthetic ethnography of cyclists on Mont Ventoux. Environ. Plan. D 24 (5), 709-732.

Spinney, J., 2015. Close encounters? mobile methods, (post)phenomenology and affect. Cult. Geogr. 22 (2), 231-246.

Straughan, E., 2012. Touched by water: the body in scuba diving. Emot. Space Soc. 5 , $19-26$.

Thrift, N., 2008. Non-representational Theory. Space/Politics/Affect. Routledge, London. 
Throsby, K., 2013. 'If I go in like a cranky sea-lion, I come out like a smiling dolphin': marathon swimming and the unexpected pleasures of being a body in water Fem. Rev. 103, 5-22.

Völker, S., Kistemann, T., 2011. The impact of blue space on human health and wellbeing - salutogenetic health effects of inland surface waters: a review. Int. J. Hyg. Environ. Health 214, 449-460.

Völker, S., Kistemann, T., 2015. Developing the urban blue: comparative health responses to blue and green urban open spaces in Germany. Health \& Place 35, 196-205.

Wheeler, B., White, M., Stahl-Timmins, W., Depledge, M., 2012. Does living by the coast improve health and wellbeing? Health \& Place 18, 1198-1201.

White, M., Pahl, S., Ashbullby, K., Herbert, S., 2013. Feelings of restoration from recent nature visits. J. Environ. Psychol. 35, 40-51. 